
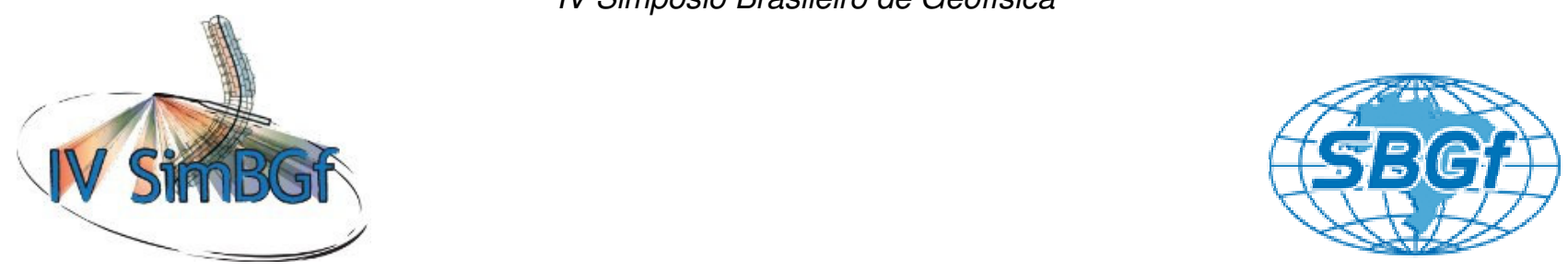

\title{
Modelamento gravimétrico tridimensional do baixo anômalo de ar-livre da Bacia de Santos.
}

Renato Cordani, Reconsult Geofísica

Copyright 2010, SBGf - Sociedade Brasileira de Geofísica

Este texto foi preparado para a apresentação no IV Simpósio Brasileiro de Geofísica, Brasília, 14 a 17 de novembro de 2010. Seu conteúdo foi revisado pelo Comite Técnico do IV SimBGf, mas não necessariamente representa a opinião da SBGf ou de seus associados. É proibida a reprodução total ou parcial deste material para propósitos comerciais sem prévia autorização da SBGf.

\section{Resumo}

O presente trabalho visa fornecer uma hipótese para a ocorrência do baixo gravimétrico de anomalia ar-livre da Bacia de Santos. Essa anomalia negativa tem cerca de $100 \mathrm{mGal}$ de amplitude e é relativamente coincidente com as recentes descobertas de óleo Bacia de Santos, na camada denominada pré-sal.

O modelo ora proposto é que o baixo é explicado pela presença de um corpo de evaporitos, composto majoritariamente por halita, que é significantemente menos denso do que os sedimentos e basaltos encaixantes.

O modelo tridimensional que fornecemos para os evaporitos pode contribuir para o conhecimento da geometria do sal, e portanto contribuir para o conhecimento do pós-sal e pré-sal.

Não foi usado nenhum dado exclusivo, ou seja, todos os dados e informações utilizadas são públicos e disponíveis para toda a comunidade geofísica.

\section{Introdução}

Qualquer método geofísico depende de um contraste de propriedade física para que 0 resultado seja representativo da geologia de sub-superfície.

No caso do presente trabalho, utilizamos técnicas de inversão 3D para testar a hipótese de que a anomalia gravimétrica negativa ar livre de mais de $100 \mathrm{mGal}$ pode ser explicada pela presença de um corpo evaporítico com um contraste negativo de densidade com relação às encaixantes.

\section{Metodologia/ Problema Investigado}

A figura 1 mostra a região do estudo. O quadrado maior (vermelho) é a área onde foi construído o modelo regional inicial. $\mathrm{O}$ polígono preto é a área do modelamento 3D.

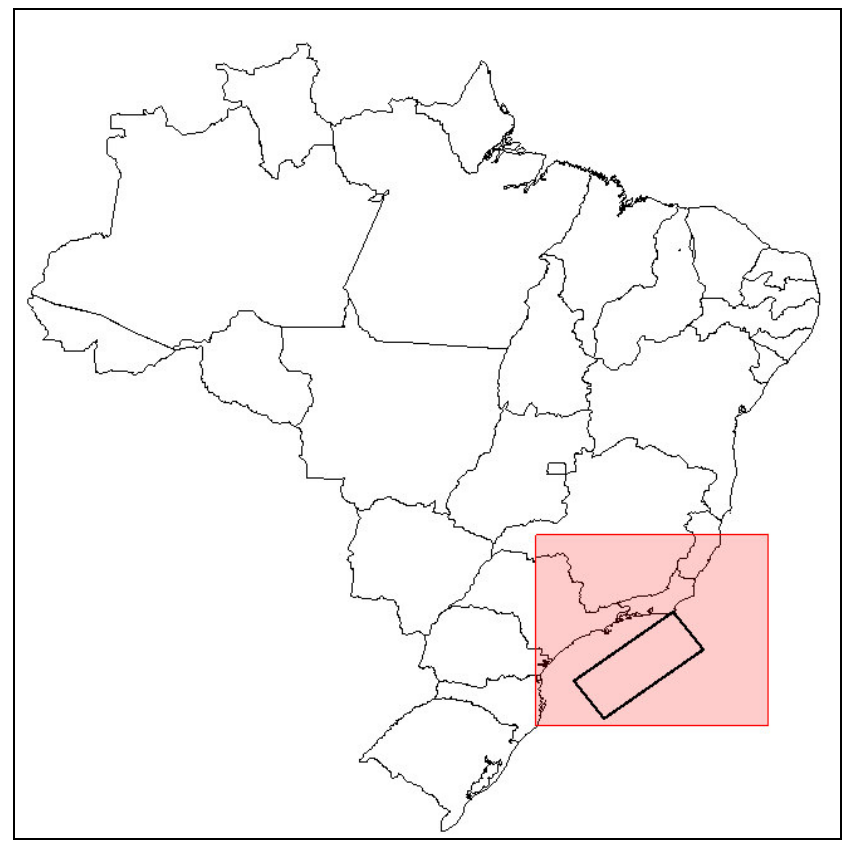

Figura 1 - a área em vermelho (apenas a parte off shore) é a área do estudo regional. O polígono preto é a área do modelamento $3 D$.

A figura 2 mostra um slide retirado do site da Petrobrás. Para efeito de comparação espacial, a figura 3 mostra a mesma área denominada pré-sal sobre a anomalia gravimétrica.

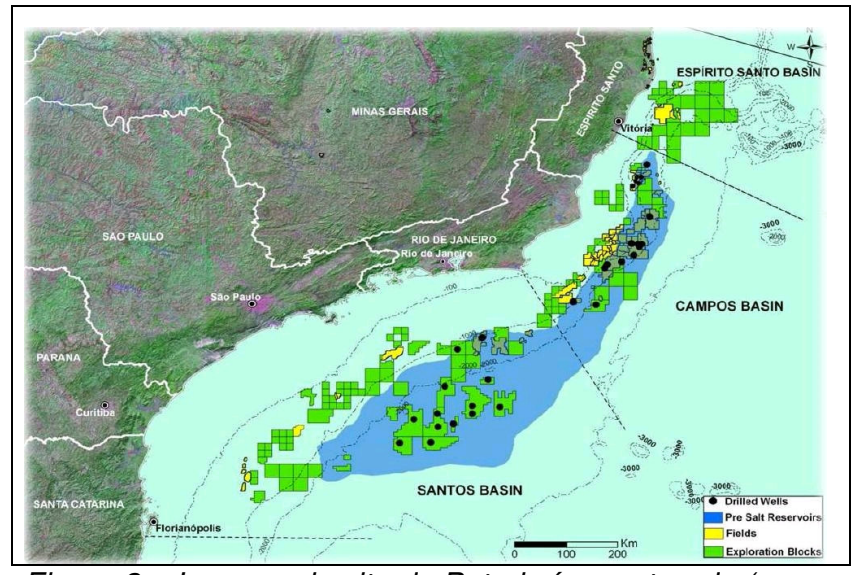

Figura 2 - Imagem do site da Petrobrás mostrando (em azul) a área aproximada das recentes descobertas. 


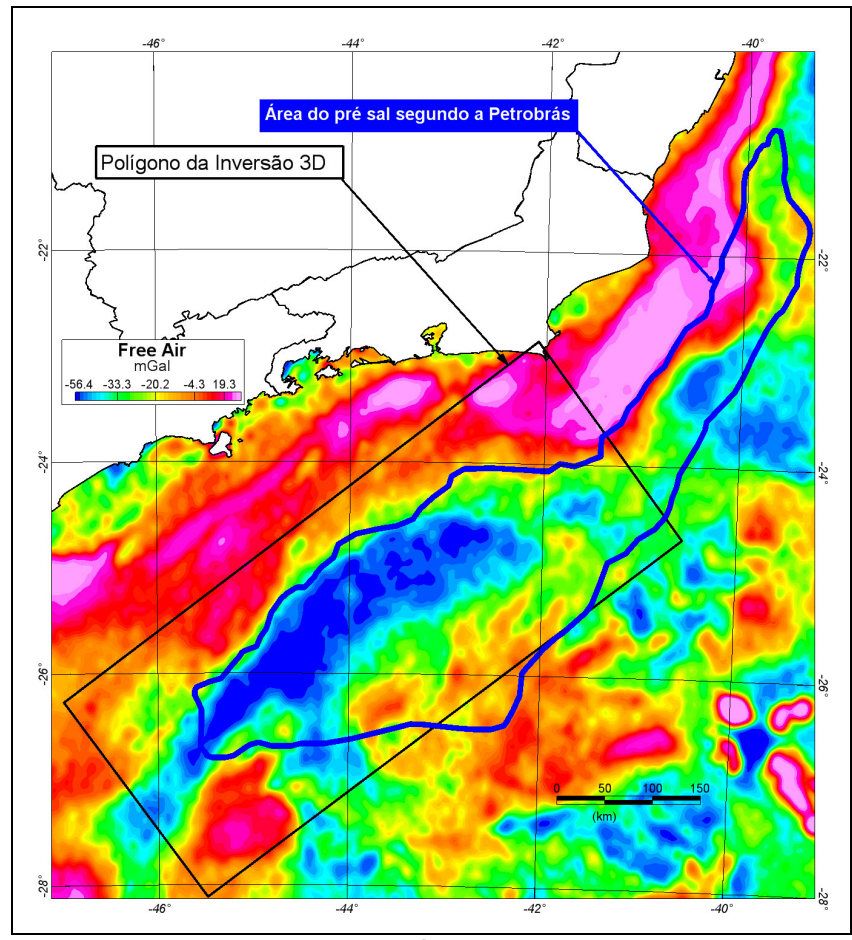

Figura 3 - Anomalia gravimétrica ar livre da região de estudo.

\section{Resultados}

Os dados gravimétricos do polígono destacado na figura 3 foram invertidos usando o software UBC-GIF (Li and Oldenburg, 1998).

As figuras 4, 5 e 6 mostram algumas imagens do modelo de densidades tridimensional obtido.

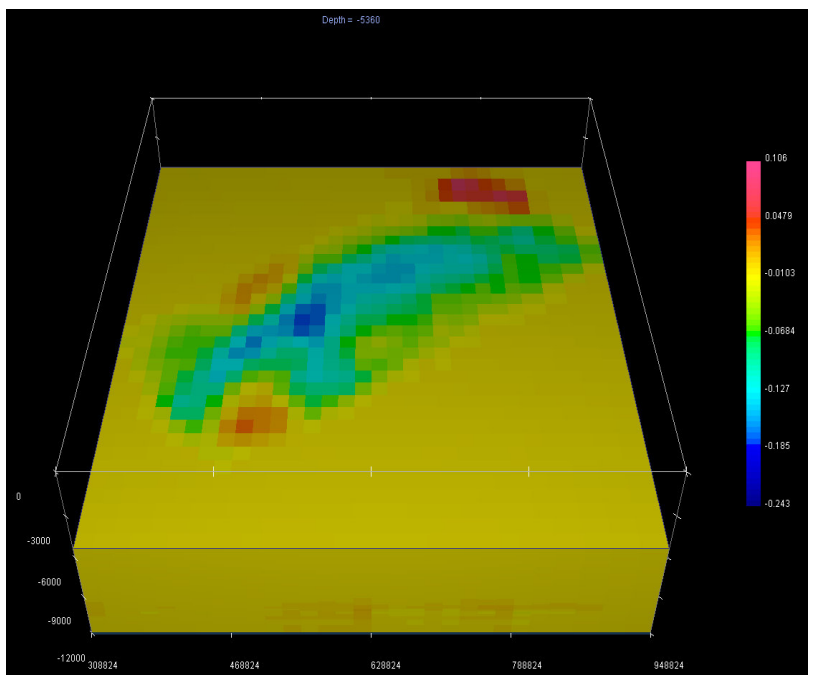

Figura 4 - corte na profundidade $5 \mathrm{~km}$ do modelo de densidades $3 D$.

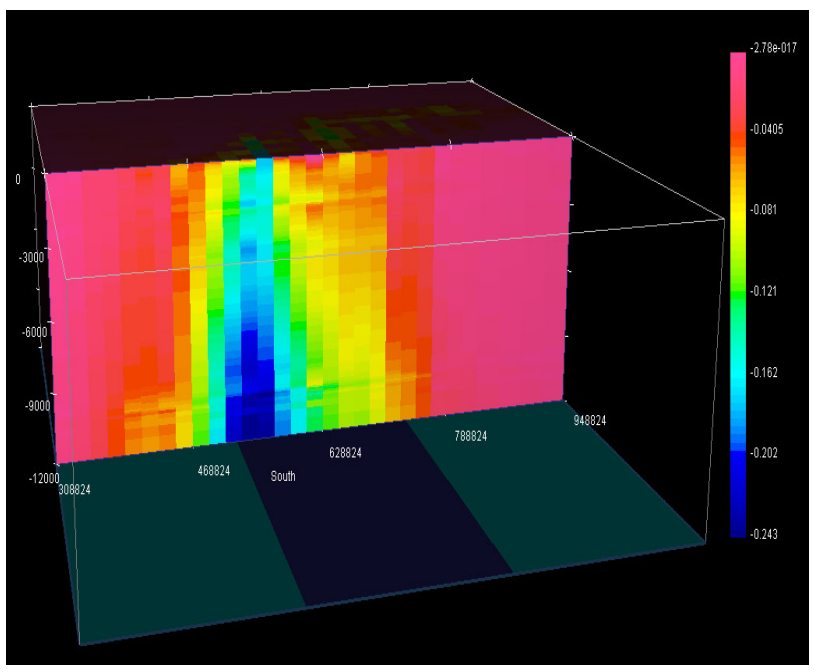

Figura 5 - seção vertical do modelo de densidades 3D.

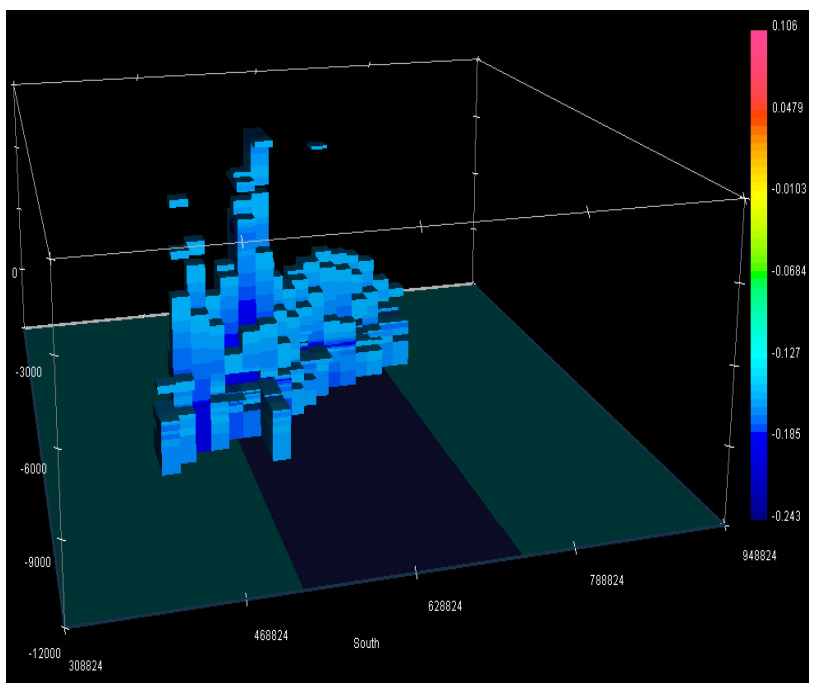

Figura 6 - visualização $3 D$ das células com contraste de densidade maior do que $0.15 \mathrm{~g} / \mathrm{cm} 3$.

A figura 7 mostra as imagens dos dados observados comparativamente aos dados sintéticos, ou seja, os dados que seriam produzidos devido ao modelo de densidade obtido. 


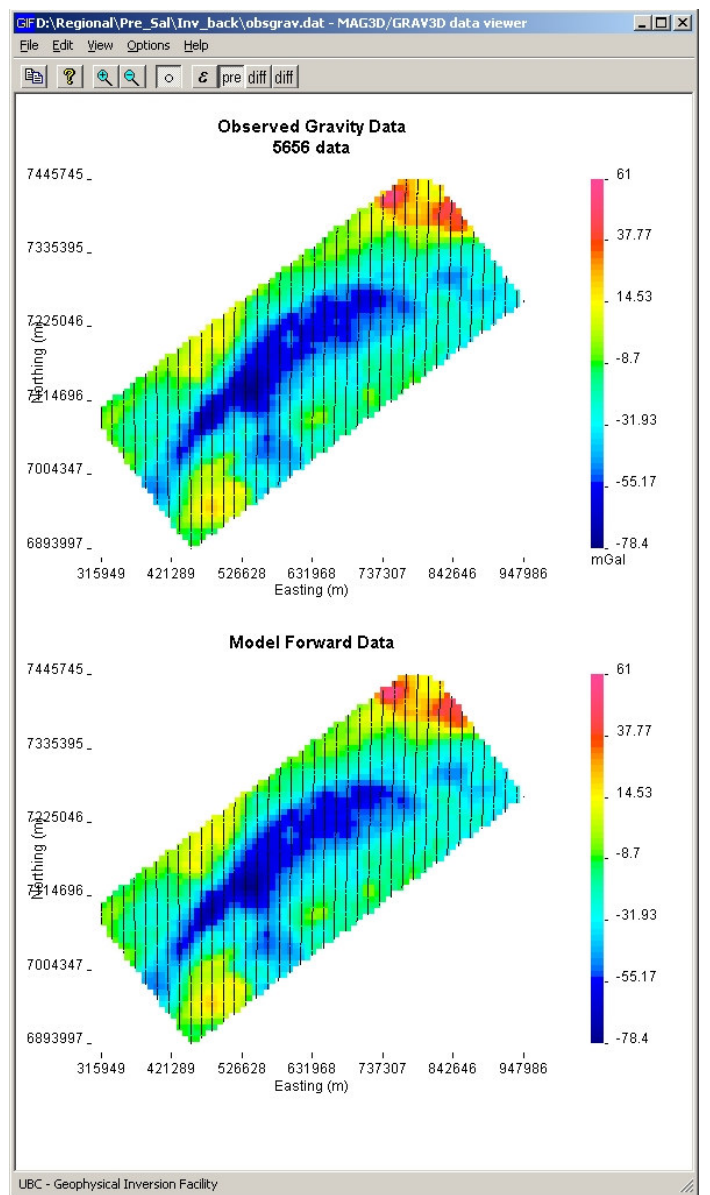

Figura 7 - comparação entre os dados reais e sintéticos.

A figura 8 mostra a visualização $3 \mathrm{D}$ das isolinhas de contraste de densidade $-0.15 \mathrm{~g} / \mathrm{cm}^{3}$ (em azul) e as Isolinhas de $+0.02 \mathrm{~g} / \mathrm{cm}^{3}$ (em vermelho). O corpo com contraste negativo (em azul) foi interpretado como sendo evaporitos com predominância de halita e o corpo com contraste positivo (em vermelho) é provavelmente uma concentração de vulcânicas (basaltos).

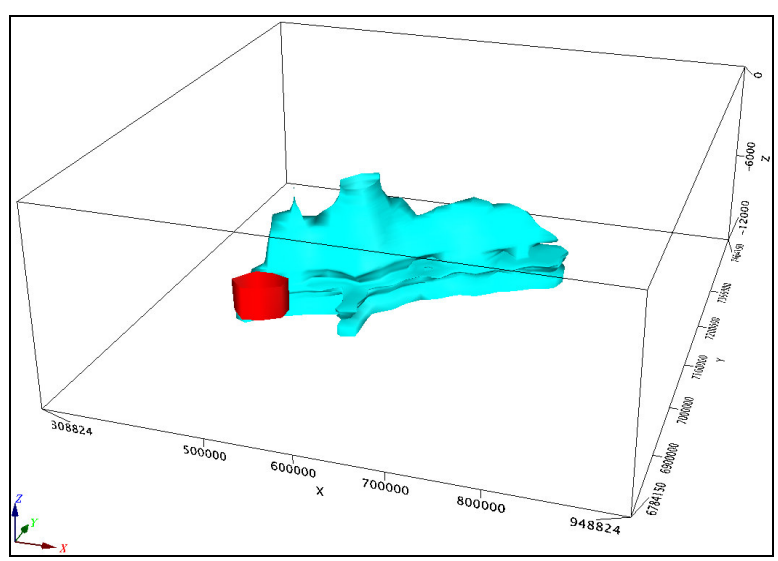

Figura 8 - visualização $3 D$ do corpo com contraste de densidade $-0.15 \mathrm{~g} / \mathrm{cm}^{3}$ (em azul) e as Isolinhas de +0.02 $\mathrm{g} / \mathrm{cm}^{3}$ (em vermelho).

\section{Discussão e Conclusões}

A dimensão da anomalia (cerca de $600 \mathrm{~km}$ na direção SW-NE) implica em que as células de inversão sejam relativamente grandes, o que torna a resolução do método adequada a estudos regionais. Para estudos que necessitem maior resolução espacial do modelo de densidades, sugerimos levantamentos gravimétricos tradicionais com espaçamentos menores entre medidas, e janelas de inversão mais reduzidas, com células de inversão menores.

Interpretamos o corpo com contraste negativo de densidade representado nas figuras acima como sendo a expressão tridimensional dos evaporitos com predominância de halita na bacia de Santos, e o corpo com contraste positivo é interpretado como sendo uma maior concentração de vulcânicas (basaltos).

O significativo contraste de densidade entre os evaporitos halíticos e os sedimentos encaixantes tornam a aplicação do modelamento gravimétrico tridimensional uma excelente ferramenta auxiliar no conhecimento geológico das bacias sedimentares off shore.

\section{Referências}

http://www.petrobras.com.br/minisite/presal/novomodelo-regulatorio/index.asp

Li Y., and Oldenburg D.W. (1998). 3D inversion of gravity data, Geoph, 63 , \#1, 109-119. 